\title{
The use of neoadjuvant lobar radioembolization prior to major hepatic resection for malignancy results in a low rate of post hepatectomy liver failure
}

\author{
Altan Ahmed ${ }^{1,2}$, John A. Stauffer ${ }^{3}$, Jordan D. LeGout ${ }^{1}$, Justin Burns ${ }^{4}$, Kristopher Croome ${ }^{4}$, \\ Ricardo Paz-Fumagalli ${ }^{1}$, Gregory Frey ${ }^{1}$, Beau Toskich ${ }^{1}$ \\ ${ }^{1}$ Department of Radiology, Mayo Clinic, Jacksonville, FL, USA; ${ }^{2}$ Department of Radiology, Moffitt Cancer Center, Tampa, FL, USA; ${ }^{3}$ Department \\ of Surgery, Mayo Clinic, Jacksonville, FL, USA; ${ }^{4}$ Department of Transplantation, Mayo Clinic, Jacksonville, FL, USA \\ Contributions: (I) Conception and design: JA Stauffer, B Toskich; (II) Administrative support: JA Stauffer; (III) Provision of study materials or patients: \\ All authors; (IV) Collection and assembly of data: JA Stauffer, A Ahmed; (V) Data analysis and interpretation: JA Stauffer, B Toskich, A Ahmed; (VI) \\ Manuscript writing: All authors; (VII) Final approval of manuscript: All authors. \\ Correspondence to: John A. Stauffer, MD. Department of Surgery, Mayo Clinic, 4500 San Pablo Rd, Jacksonville, FL 32224, USA. \\ Email: stauffer.john@mayo.edu.
}

Background: Neoadjuvant yttrium-90 transarterial radioembolization (TARE) is increasingly being used as a strategy to facilitate resection of otherwise unresectable tumors due to its ability to generate both tumor response and remnant liver hypertrophy. Perioperative outcomes after the use of neoadjuvant lobar TARE remain underinvestigated.

Methods: A single center retrospective review of patients who underwent lobar TARE prior to major hepatectomy for primary or metastatic liver cancer between 2007 and 2018 was conducted. Baseline demographics, radioembolization parameters, pre- and post-radioembolization volumetrics, intra-operative surgical data, adverse events, and post-operative outcomes were analyzed.

Results: Twenty-six patients underwent major hepatectomy after neoadjuvant lobar TARE. The mean age was 58.3 years (17-88 years). $62 \%$ of patients $(n=16)$ had primary liver malignancies while the remainder had metastatic disease. Liver resection included right hepatectomy or trisegmentectomy, left or extended left hepatectomy, and sectorectomy/segmentectomy in $77 \%(n=20), 8 \%(n=2)$, and $15 \%(n=4)$ of patients, respectively. The mean length of stay was 8.3 days (range, 3-33 days) and there were no grade IV morbidities or 90-day mortalities. The incidence of post hepatectomy liver failure (PHLF) was $3.8 \%(n=1)$. The median time to progression after resection was 4.5 months (range, 3.3-10 months). Twenty-three percent ( $\mathrm{n}=6)$ of patients had no recurrence. The median survival was 28.9 months (range, 16.9-46.8 months) from major hepatectomy and 37.6 months (range, 25.2-53.1 months) from TARE.

Conclusions: Major hepatectomy after neoadjuvant lobar radioembolization is safe with a low incidence of PHLF.

Keywords: Radioembolization; post hepatectomy liver failure (PHLF); major hepatectomy; radiation lobectomy

Submitted Nov 11, 2020. Accepted for publication Feb 15, 2021.

doi: 10.21037/jgo-20-507

View this article at: http://dx.doi.org/10.21037/jgo-20-507 


\section{Introduction}

Complex hepatic resections for primary and metastatic malignancies are now safely performed in high volume centers with a perioperative mortality of less than $5 \%(1-3)$. Unfortunately, most patients with primary and metastatic hepatic malignancies are not conventional surgical candidates at the time of diagnosis. Tumor size, multiplicity, location, inadequate residual liver function, patient comorbidities, and uncertain tumor biology may all preclude the gold standard of resection (4-9).

Insufficient future liver remnant (FLR) is the dominant contributing factor to post hepatectomy liver failure (PHLF), a major source of post-operative morbidity and mortality $(10,11)$. Candidacy for hepatic resection in current practice is largely based upon the volume of the FLR prior to resection with limited insight of the FLR functional capacity $(12,13)$.

Interventions to increase FLR volume and reduce the probability for PHLF include portal vein embolization (PVE), hepatic vein embolization (HVE), associating liver partition and portal vein ligation with staged hepatectomy (ALPPS), and lobar transarterial radioembolization (TARE), also referred to as radiation lobectomy (14). While PVE has traditionally been utilized to increase FLR, it carries a risk of tumor progression during the hypertrophy period (15-17). Systemic chemotherapy may mitigate disease progression during post PVE hypertrophy, but cytotoxic effects can compromise FLR function (18). ALPPS can induce a significant volume of liver hypertrophy in several days, but is associated with a mortality as high as $9.6 \%$ and discordance between FLR volume and liver function has been reported (12,13,19-24).

Lobar TARE has been shown to simultaneously generate treated lobe volume reduction, contralateral lobe hypertrophy, and high rates of tumor response. The hepatic parenchymal involution associated with ablative radiation exposure has been speculated to provide additional assurance against PHLF. These properties of TARE have generated interest in its application as a neoadjuvant to hepatectomy (25-29).

Early studies suggest that neoadjuvant TARE often achieves remnant liver hypertrophy volumes that are comparable to PVE while providing tumor control and that surgical resection after radioembolization is safe $(27,30)$. There is limited data regarding perioperative outcomes of liver resection and incidence of PHLF following neoadjuvant lobar TARE (31-34). This study will present the surgical experience with major hepatectomy following neoadjuvant lobar TARE for malignant neoplasms of the liver.

We present the study in accordance with the STROBE reporting checklist. Available at: http://dx.doi.org/10.21037/ jgo-20-507.

\section{Methods}

This study was performed with Institutional Review Board approval (No. 19-009890) and individual consent for this retrospective analysis was waived. The study was conducted in accordance with the Declaration of Helsinki (as revised in 2013).

\section{Patient evaluation}

A retrospective review of all patients undergoing hepatic resections was performed at a single tertiary referral center. A prospectively populated institutional database was used to identify patients who underwent neoadjuvant lobar TARE prior to hepatic resection for primary or metastatic liver malignancy. All care plans were approved by a multidisciplinary tumor board.

From 2007 to 2018, 722 patients who underwent major hepatic resection were reviewed. Patients who received pre-operative lobar TARE with or without an adjunctive segmental tumor radioembolization, and subsequent major hepatic resection were included. Patient demographics, medical history, radiologic data pre- and post-treatment, liver volumetrics, radioembolization dosimetry, preoperative systemic treatment, intra-operative surgical data, and post-operative outcomes were recorded. Adverse events following TARE were classified according to the National Cancer Institute Common Terminology Criteria for Adverse Events (CTCAE) version 5.0 (35) from the time of TARE to resection. Post-operative complications were graded according to the Clavien-Dindo classification for a 90-day time period after surgery (36). The presence and degree of post hepatectomy specific complications such as bile leak, hemorrhage, and liver failure was assessed based on the International Study Group of Liver Surgery (ISGLS) classification system (37-39). Tumor size was calculated by the largest maximum lesion (in the instance of multiple lesions) on baseline imaging. Major hepatic resection was defined as resection of three or more Couinaud segments according to the Brisbane 2000 system of nomenclature (40). 
Table 1 Dosimetry for 26 patients undergoing hepatic resection after TARE

\begin{tabular}{lc}
\hline Variable & $\mathrm{N}=26$ \\
\hline Y90 activity, mean, Gbq [range] & $2.9[1-9]$ \\
Dosage, mean, Gy [range] & $147.5[48-364]$ \\
Treated absolute volume of liver, mean, & $1,062[354-2,035]$ \\
$\mathrm{mL}$ [range] & \\
Treated percentage volume of liver, & $59.3 \%[14-83 \%]$ \\
mean, [range] & \\
\hline
\end{tabular}

TARE, transarterial radioembolization; Gbq, Gigabecquerel.

Table 2 Demographics for 26 patients undergoing hepatic resection after TARE

\begin{tabular}{lc}
\hline Variable & $\mathrm{N}=26^{\dagger}$ \\
\hline Age, years, mean (range) & $58.3[17-88]$ \\
Body mass index, mean (range) & $26[17-40]$ \\
Male & $9(34.6)$ \\
Liver disease & $5(19.2)$ \\
Steatosis & $1(3.8)$ \\
Fibrosis (minimal) & $1(3.8)$ \\
Cirrhosis/Mild portal hypertension & $4(15.4)$ \\
ASA & \\
II & $3(11.5)$ \\
III & $20(76.9)$ \\
IV & $3(11.5)$ \\
\hline
\end{tabular}

${ }^{\dagger}$, values reported as $n(\%)$ unless otherwise indicated. ASA, American Society of Anesthesiologists score; TARE, transarterial radioembolization.

\section{TARE}

TARE was performed using a previously published methodology $(41,42)$. All patients underwent planning angiography to evaluate the hepatic arterial anatomy. Treatment volumes were calculated using pre-TARE cross sectional imaging for patients treated prior to 2016 and using intra-procedural cone beam CT thereafter. Technetium labeled macroaggregated albumin was administered as a surrogate for radioembolization microspheres. Dosimetry was calculated using the Medical Internal Radiation Dose (MIRD) or Body Surface Area (BSA) methodology for glass (TheraSphere ${ }^{\mathrm{TM}}$, Boston
Scientific, Marlborough, MA) and resin (SIR-Spheres ${ }^{\circledR}$, Sirtex, Woburn, MA, USA) microspheres, respectively. All patients received TARE to the planned hepatic future resection site (FRS) with or without an additional selective dose to the tumor(s). The target doses are summarized in Table 1. TARE was used after PVE to salvage an inadequate volumetric response. In some instances, PVE was utilized after TARE per the surgeon's preference.

\section{Imaging and volumetrics}

Multiphase CT or MRI was performed at baseline, at 1 month following TARE, and approximately every 3 months until resection. Preoperative imaging within 30 days of resection was used to calculate the FLR, degree of hypertrophy $(\mathrm{DH})$, and kinetic growth rate (KGR) in relation to baseline imaging. Hepatic volumetrics were measured using iNtuition (TeraRecon, Durham, NC, USA) with hand drawn regions of interest over the FRS, FLR, and total liver. FLR was calculated as a ratio, expressed as a percentage, of the FLR over total liver volume. DH was calculated by dividing the absolute difference between the pre- and post-TARE FLR by the pre-TARE FLR. KGR was calculated by dividing the DH by the time interval (in weeks) from TARE until preoperative imaging. A single patient was excluded from the volumetric analysis as staged segmental resections were performed in the FLR prior to major hepatectomy.

\section{Statistical analysis}

Data analysis was performed using R v2020-02-29 (R Foundation for Statistical Computing, Vienna, Austria). Continuous variables were described as median values with interquartile range (IQR) or mean values with range. Categorical variables were described as frequencies with percentages. Normal distributions were reported as mean while non-normal distributions were reported as medians with IQR, unless specified.

\section{Results}

Twenty six patients underwent neoadjuvant lobar TARE prior to major hepatic resection during the study period. Most patients $(\mathrm{n}=17)$ underwent liver resection between 2016 and 2018. Patient demographics are summarized in Table 2. Five patients underwent percutaneous liver biopsy prior to intervention. Of these, four patients with 
Table 3 Operative variables for 26 patients undergoing hepatic resection after TARE

\begin{tabular}{lc}
\hline Variable & $\mathrm{N}=26^{\dagger}$ \\
\hline Operative time, min, mean (range) & $311[133-430]$ \\
Estimated blood loss, $\mathrm{mL}$, mean (range) & $1,173[100-11,200]$ \\
Minimally invasive technique & $8(30.8)$ \\
Right hepatectomy/trisegmentectomy & $20(76.9)$ \\
Left hepatectomy/extended left & $2(7.7)$ \\
Sectorectomy/segmentectomy & $4(15.4)$ \\
\hline${ }^{\dagger}$, values reported as $\mathrm{n}(\%)$ unless otherwise indicated. TARE, \\
transarterial radioembolization.
\end{tabular}

Table 4 Pathology findings for 26 patients undergoing hepatic resection after TARE

\begin{tabular}{lc}
\hline Variable & $\mathrm{N}=26^{\dagger}$ \\
\hline Hepatocellular carcinoma (HCC) & $9(34.6)$ \\
Metastatic colorectal adenocarcinoma & $6(23.1)$ \\
Intrahepatic cholangiocarcinoma (iCCA) & $6(23.1)$ \\
Metastatic carcinoid tumor & $2(7.7)$ \\
Metastatic melanoma & $1(3.8)$ \\
Mixed iCCA/HCC & $1(3.8)$ \\
Gallbladder carcinoma & $1(3.8)$ \\
Margins & \\
R0 & $25(96.2)$ \\
R1 & $1(3.8)$ \\
\hline
\end{tabular}

${ }^{\dagger}$, values reported as $\mathrm{n}(\%)$ unless otherwise indicated. TARE, transarterial radioembolization.

hepatocellular carcinoma demonstrated signs of cirrhosis and one patient with cholangiocarcinoma demonstrated steatosis and minimal portal fibrosis (Table 2). The indications for TARE were: inadequate FLR volume for resection $(n=19$, $73.1 \%$ ), prior failed PVE ( $\mathrm{n}=4,15.4 \%$ ), downstaging for potential orthotopic liver transplantation $(\mathrm{n}=1,3.8 \%)$, symptom control from tumor $(\mathrm{n}=1,3.8 \%)$, and recent myocardial infarction with stent placement $(\mathrm{n}=1,3.8 \%)$. Approximately $85 \%(n=22)$ of patients also had high risk tumor biology, per multidisciplinary consensus, that would benefit from a biologic test of time. The majority $(n=20$, $76.9 \%$ ) of patients had pre-operative Albumin-Bilirubin grades of A1 or A2 with a median tumor size of $6.7 \mathrm{~cm}$ $(3.7-10.2 \mathrm{~cm})$. Tumors were right sided, bilobar, or central in $20(76.9 \%), 5(19.2 \%)$, and $1(3.8 \%)$ patients, respectively. Eighteen patients $(69.2 \%)$ had solitary tumors. Glass and resin microspheres were used in $21(80.8 \%)$ and $5(19.2 \%)$ patients, respectively. Repeat TARE was performed on $2(7.7 \%)$ patients in the setting of large $(>10 \mathrm{~cm})$ primary tumors with partial response to initial TARE. PVE was performed in $6(23.1 \%)$ patients after TARE. Four (15.4\%) patients underwent prior liver directed intra-arterial therapy with chemoembolization $(\mathrm{n}=3,11.5 \%)$ or bland embolization $(\mathrm{n}=1,3.8 \%)$ for lesions in the same hepatic lobe subsequently salvaged with TARE. Nineteen $(73.1 \%)$ patients received concurrent systemic therapy including $5 \mathrm{FU}$ based regiments $(\mathrm{n}=7,26.9 \%)$, Gemcitabine/Cisplatinum ( $\mathrm{n}=6,23.1 \%)$, Sorafenib $(n=3,11.5 \%)$, octreotide analogue $(n=2,7.7 \%)$, and immunotherapy $(\mathrm{n}=1,3.8 \%)$.

Surgical details are noted in Table 3. Eleven (42.4\%) patients underwent additional resections including bowel resection $(n=4,15.4 \%)$, portal vein resection $(n=2,7.7 \%)$, diaphragmatic resection $(\mathrm{n}=2,7.7 \%)$, extrahepatic bile duct resection with Roux-en-Y reconstruction $(\mathrm{n}=2,7.7 \%)$, and right adrenalectomy $(\mathrm{n}=1,3.8 \%)$. A staged resection was performed in one $(3.8 \%)$ patient with bilobar colorectal metastasis who underwent left lateral hepatectomy prior to right hepatectomy as has been previously described (43). The mean time from TARE to surgery was 235 days (107636 days).

Pathology of the underlying disease is given in Table 4 . The majority of patients had primary hepatic malignancy $(\mathrm{n}=16,62 \%)$. Of available $(\mathrm{n}=17)$ histologic descriptions of tumor necrosis, $76 \%(\mathrm{n}=13)$ demonstrated extensive or complete pathologic necrosis.

There were no grade III or higher bilirubin toxicities after TARE prior to hepatic resection. One patient developed grade III diarrhea and another developed grade III abdominal pain after TARE. Post operative outcomes are given in Table 5. The majority of patients had no major complications $(\mathrm{n}=20,76.9 \%)$ and had hospitalizations less than 9 days $(\mathrm{n}=23,88.5 \%)$. The incidence of PHLF was $3.8 \%(n=1)$. There were no reoperations or mortalities within 90 days.

A summary of liver volumetrics is given in Table 6. The mean FLR volume/percentage was $671 \mathrm{~mL}(310-1,608 \mathrm{~mL}) / 38.4 \%$ (16-86\%) before TARE and $857 \mathrm{~mL}(372-1,398 \mathrm{~mL}) / 52.7 \%$ (31-92\%) after TARE. The mean DH and KGR was 45.8 [0-119] and 1.7 [0-6], respectively.

TARE dosimetry and target volumes are given in Table 1. The mean treated liver volume was $1,062 \mathrm{~mL}(354-2,035 \mathrm{~mL})$ and mean treated liver percent was $59.3 \%(14-83 \%)$. The 
mean Y90 dose was 147.5 Gy (48-364 Gy).

At the time of manuscript preparation, 15 (58\%) patients were still alive and 11 (42\%) died of disease progression. Six (23\%) patients had no recurrence and the other $20(77 \%)$ patients had recurrence identified at a median interval of 4.5 months (3.3-10 months) from the index operation. Eleven of these patients had distant metastases with no

Table 5 Post-operative outcomes (90-day) for 26 patients undergoing hepatic resection after TARE

\begin{tabular}{ll}
\hline Variable & $\mathrm{N}=26^{\dagger}$ \\
\hline Clavien-Dindo complication & $6(23.1)$ \\
III & 0 \\
IV/N & $1(3.8)$ \\
Post hepatectomy hepatic failure & $1(3.8)$ \\
Grade B & $2(7.7)$ \\
Post hepatectomy bile leak & $1(3.8)$ \\
Grade B & $1(3.8)$ \\
Grade C & 0 \\
Reoperation & $8.3[3-33]$ \\
Length of stay, days, mean (range)
\end{tabular}

${ }^{\dagger}$ Values reported as No. (\%) unless otherwise indicated. TARE, transarterial radioembolization. evidence of remnant liver disease. Nine patients had hepatic recurrence, four of them concurrently with distant disease. Median overall survival was 28.9 months (16.9-46.8 months) from the index operation and 37.6 months (25.2-53.1 months) from TARE.

\section{Discussion}

Surgical resection remains the gold standard local treatment of primary and metastatic liver malignancy. Many patients are not candidates for resection at presentation due to disease stage, performance status, comorbidities, anatomic factors, or insufficient FLR. PVE and ALPPS have been utilized in patients with inadequate FLR but are associated with a risk of tumor progression and significant morbidity/mortality, respectively $(15,16,44-48)$ (Figure 1). Furthermore, post-operative liver failure remains the most common morbidity after both PVE and ALPPS $(19,20)$.

TARE has been shown to ablate both tumoral and adjacent liver parenchyma which enables an extended FLR hypertrophy time compared with PVE $(29,49)$. In appropriately selected patients, this allows further assessment of tumor biology and stage while controlling tumor. Neoadjuvant lobar TARE, also referred to as radiation lobectomy, has seen increased utilization over the past decade. Early experience with lobar TARE

Table 6 Liver volumetric data for 26 patients undergoing hepatic resection after TARE

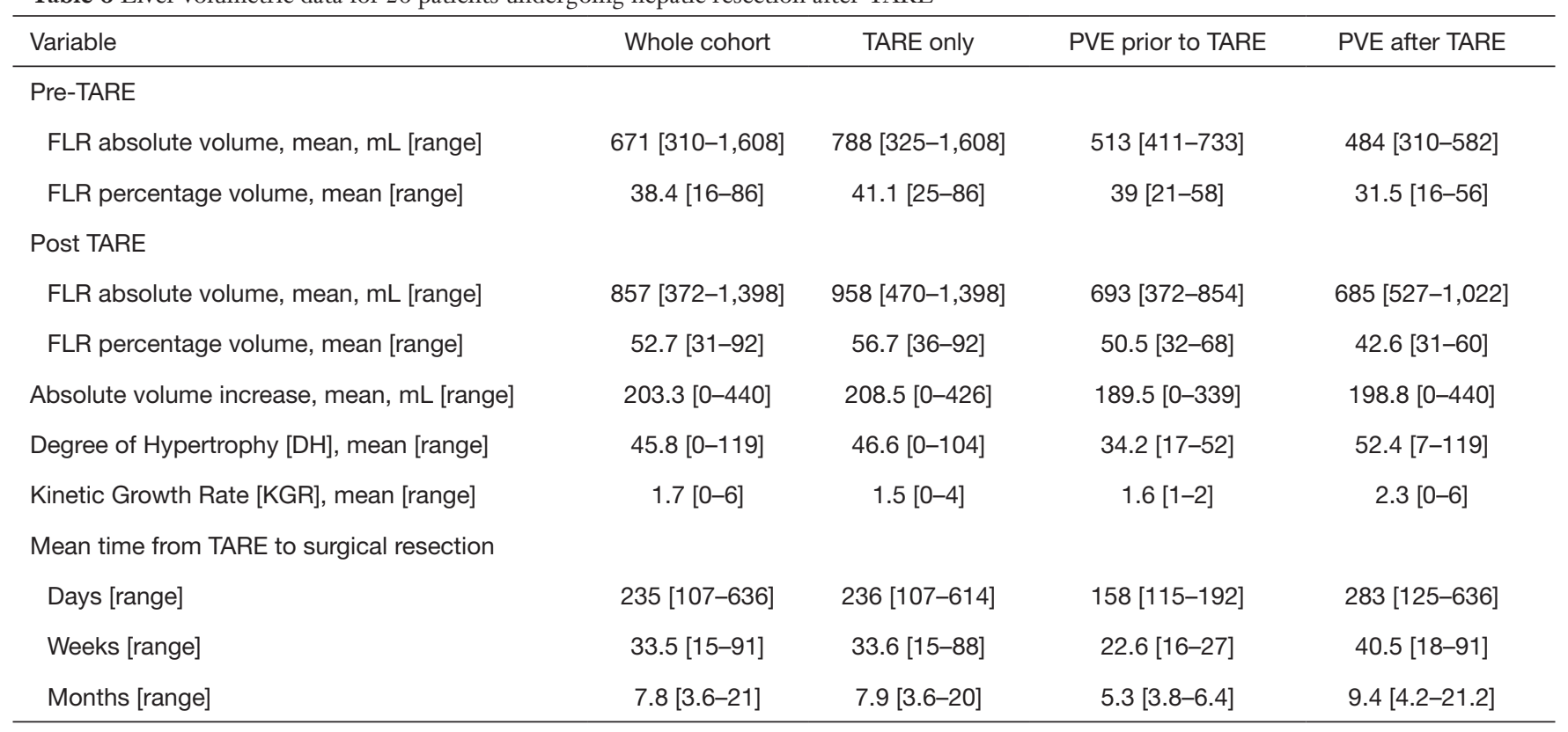

TARE, transarterial radioembolization; PVE, portal vein embolization. 

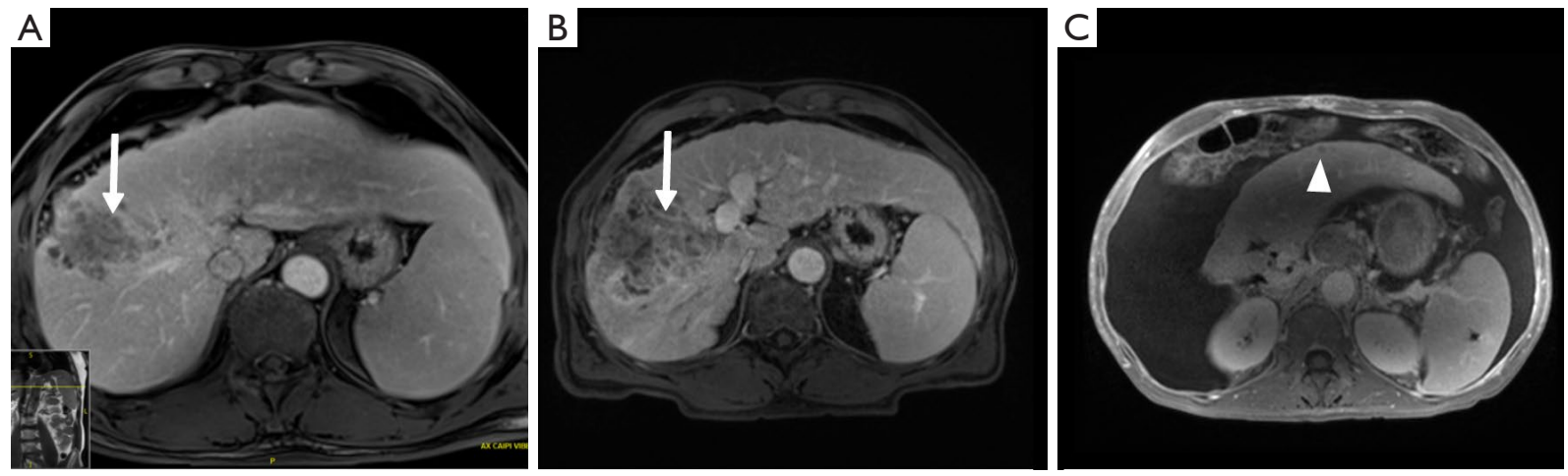

Figure 1 Post contrast MRI demonstrating a cirrhotic liver with hepatocellular carcinoma (arrow) in the right hepatic lobe (A). Post contrast MRI obtained one month after PVE demonstrates progression of tumor (arrow) and an FLR volume of 40\% (B). Post contrast MRI obtained 3 months after right hepatectomy demonstrates liver failure with ascites and a subcentimeter tumor recurrence (arrow head) (C). PVE, portal vein embolization; FLR, future liver remnant.
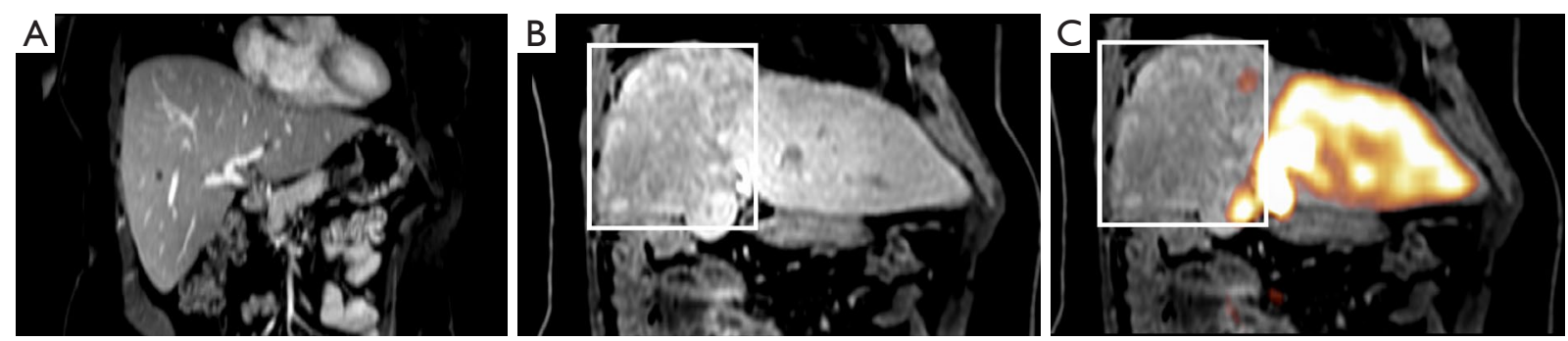

Figure 2 Post contrast MRI prior to neoadjuvant right lobar TARE demonstrates a small FLR (A). Hepatobiliary phase MRI post hepatocyte contrast administration obtained 6 months after initial TARE demonstrates FLR hypertrophy and poor biliary excretory function of the FRS (square) (B). FRS devitalization is supported by reduced radiotracer activity (square) using 99mTc-Mebrofenin MRI fusion (C). TARE, transarterial radioembolization; FLR, future liver remnant; FRS, future resection site.

demonstrated that it was safe, effectively controls tumor, and produces contralateral lobar hypertrophy volume comparable to PVE but at slower rates (26,27,29-31,50,51).

Liver volumetrics and growth kinetics have been used as surrogates of post-operative liver function, but the variability of a patient's hepatic substrate is not completely captured by these indirect measures of physiology. Liver volumetrics may be prone to additional error in patients with underlying liver disease and previous systemic therapy. It is known that PVE and ALLPS reduce FRS hepatic function however, pre-operative devitalization of the FRS is not achieved with either of these techniques and liver failure remains a major associated morbidity and mortality. TARE induced devitalization of the FRS may represent a more accurate surrogate for post resection liver function as the patient is not physiologically relying on the FRS at the time of surgery (Figures 2,3). This is supported by the low incidence of PHLF in our cohort (3.8\%). Conceptually, growth metrics such as DH and KGR may be less informative of the risk of PHLF in the setting of a devitalized FRS as the liver may not hypertrophy beyond what is adequate for the individual patient.

Although FLR hypertrophy is generally slower after TARE than PVE, the high rates of tumor response observed in this study allowed for extended hypertrophy time without local progression. While our study did not specifically confirm devitalization of the FRS using functional agents such as hepatocyte specific MRI contrast, mebrofenin, or methecetin $(52,53)$, only a single patient who underwent neoadjuvant right lobar TARE experienced PHLF (grade B) in our cohort. The liver failure eventually progressed culminating with the patient's death approximately 19 months after surgery.

Tumor biology plays a critical role in patient outcomes 

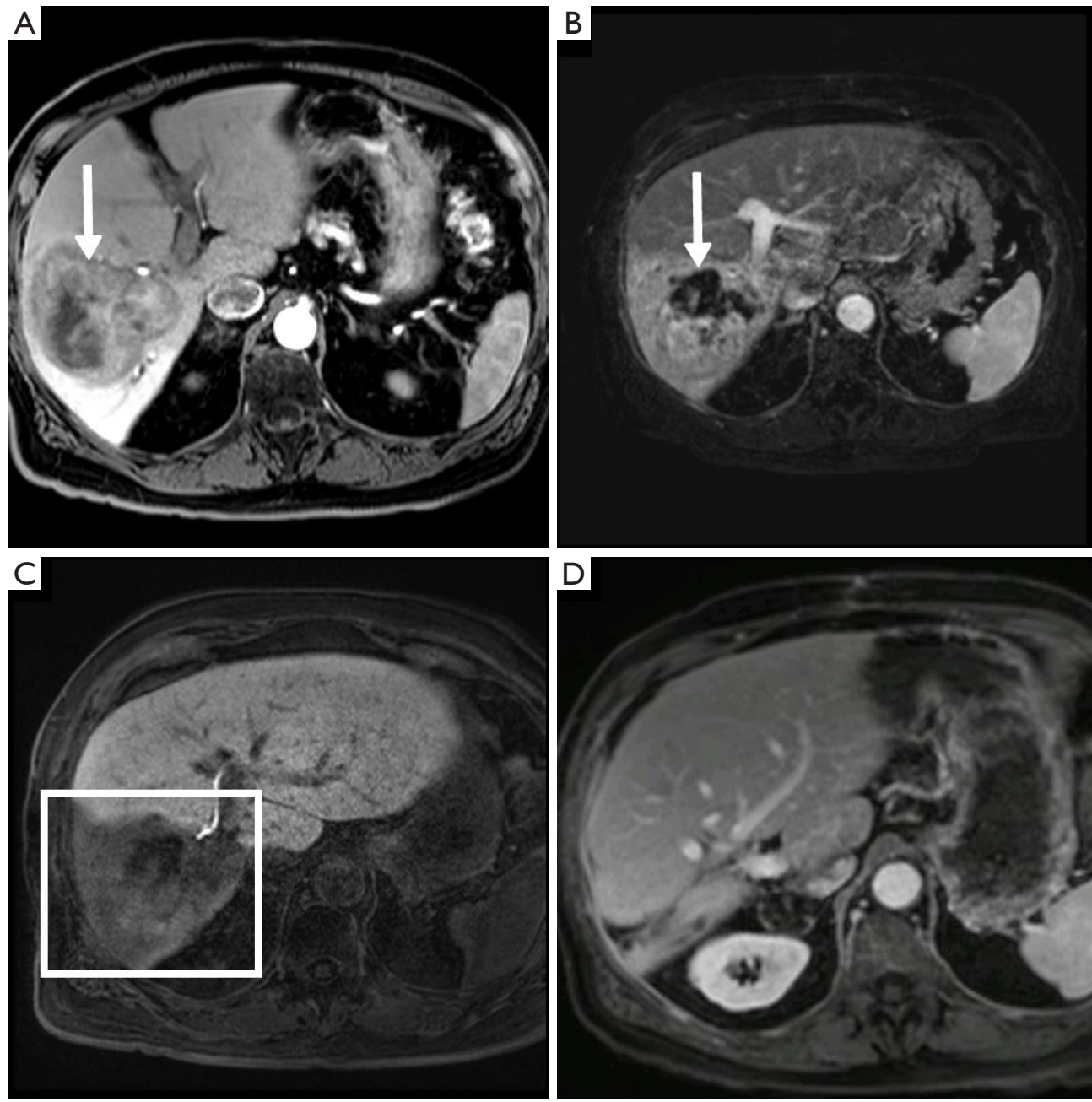

Figure 3 Post contrast MRI demonstrating a right lobe hepatocellular carcinoma (arrow) with a small FLR (A). Post hepatocyte contrast administration MRI obtained 6 months after initial TARE demonstrates tumor necrosis (arrow) (B), interval FLR hypertrophy, and poor excretory function of the FRS (square) (C). Post contrast MRI image obtained 14 months after resection demonstrates no tumor recurrence or evidence of liver failure (D). The patient remains free of recurrence 30 months after resection. FLR, future liver remnant; TARE, transarterial radioembolization; FRS, future resection site.

after resection. In metastatic colorectal cancer to the liver, RAS mutations have been associated higher rates of recurrence and shorter post recurrence survival (54-56). In hepatocellular carcinoma, tumors with micro- and macrovascular invasion and higher levels of pre-intervention alpha fetoprotein have been shown to be associated with higher rates of recurrence (57-59). Prolonged observation enabled by neoadjuvant TARE may facilitate a more thorough assessment of initially occult intrahepatic and extrahepatic disease.

Pre-operative comorbidity indices and performance status have been shown to be associated with post-operative morbidity and mortality (60-65). In addition to assessment of tumor biology over a longer time period, neoadjuvant TARE also provides an opportunity to consolidate disease and optimize medical comorbidities prior to resection.

There are technical aspects to hepatic resection after neoadjuvant TARE that warrant consideration by the surgeon. As with any neoadjuvant radiation therapy, a longer observation period prior to resection allows for the development of treatment associated adhesions. TARE can create dense fibrotic changes within and adjacent to the liver, particularly with high dose administrations in peripherally located tumors. From our experience, large 
lesions located in the dome may require en bloc partial diaphragm resection. An exophytic lesion located in the posterior lobe required an ipsilateral adrenalectomy in one case. Additionally, lesions treated with high dose TARE in the undersurface of the liver may induce radiation changes to adjacent viscera. TARE can also complicate margin analysis. While there is often a clear radiographic and superficial capsular demarcation between the treated and non-treated lobe, the contrast is not as well defined within the liver parenchyma. Given this observation, our practice minimizes TARE particle volumes to prevent irradiation of the central portal triad (66). Depending on institutional policy, frozen section analysis cannot be utilized if surgery is performed soon after TARE due to risk of equipment contamination with radioactive microspheres. In these cases, intraoperative margin analysis may be performed by gross inspection and touch preparation. Permanent histologic examination with final margin analysis can proceed in a normal fashion, albeit several days after the hepatectomy.

Despite offering both FLR hypertrophy and tumor control in the FRS, neoadjuvant TARE has some disadvantages. TARE is more costly when compared to outpatient PVE performed with moderate sedation. While single day TARE is increasingly utilized, two treatment sessions over separate days remains the most common approach (67). In addition, the increased time for FLR hypertrophy may not be suitable for certain patients within a more narrow systemic therapy window for resection. TARE is more susceptible than PVE to variances in technique owing to a complex interplay of factors including patient selection, underlying liver disease, microsphere specific activity and number, microsphere preferential flow, and timing with vasoactive systemic therapies. Neoadjuvant TARE dosimetry is currently being investigated and best practice has not yet been established, but there is strong suggestion of both parenchymal and tumor dose thresholds associated with the $\mathrm{DH}$ and tumor response, respectively (68-71).

Limitations of our study include its retrospective nature with inclusion of many primary and secondary liver malignancies and small cohort size. The study was not performed as an intention to treat analysis and patients who received TARE who did not ultimately receive resection were not included. TARE dosimetry was estimated using the MIRD or BSA models and post TARE dose distribution was not available for the entire cohort. As in most evolving therapies, practice evolution presents heterogeneities that limit the power of a retrospective analysis. As such, PVE was also utilized for hepatic conditioning post radioembolization in some patients. Lastly, the degree of post TARE tumor necrosis did not receive dedicated pathology reassessment, but this is outside the scope of this study.

\section{Conclusions}

The incidence of PHLF and operative complications in patients treated with neoadjuvant lobar radioembolization is low. This treatment provides a high degree of preoperative tumor control and FLR hypertrophy in otherwise unresectable patients.

\section{Acknowledgments}

Funding: None.

\section{Footnote}

Reporting Checklist: The authors have completed the STROBE reporting checklist. Available at: http://dx.doi. org/10.21037/jgo-20-507

Data Sharing Statement: Available at: http://dx.doi. org/10.21037/jgo-20-507

Peer Review File: Available at: http://dx.doi.org/10.21037/ jgo-20-507

Conflicts of Interest: All authors have completed the ICMJE uniform disclosure form (available at: http://dx.doi. org/10.21037/jgo-20-507). Beau Toskich is an advisor to Boston Scientific, Astra Zeneca, Johnson and Johnson, and Histosonics. The other authors have no conflicts of interest to declare.

Ethical Statement: The authors are accountable for all aspects of the work in ensuring that questions related to the accuracy or integrity of any part of the work are appropriately investigated and resolved. The study was conducted in accordance with the Declaration of Helsinki (as revised in 2013). Institutional review board approval was obtained (No. 19-009890) and individual consent for this retrospective analysis was waived.

Open Access Statement: This is an Open Access article distributed in accordance with the Creative Commons Attribution-NonCommercial-NoDerivs 4.0 International License (CC BY-NC-ND 4.0), which permits the non- 
commercial replication and distribution of the article with the strict proviso that no changes or edits are made and the original work is properly cited (including links to both the formal publication through the relevant DOI and the license). See: https://creativecommons.org/licenses/by-nc-nd/4.0/.

\section{References}

1. Jarnagin WR, Fong Y, DeMatteo RP, et al. Improvement in Perioperative Outcome After Hepatic Resection. Ann Surg 2002;236:397-406.

2. Nguyen KT, Gamblin TC, Geller DA. World review of laparoscopic liver resection-2,804 patients. Ann Surg 2009;250:831-41.

3. Aloia TA, Fahy BN, Fischer CP, et al. Predicting poor outcome following hepatectomy: Analysis of 2313 hepatectomies in the NSQIP database. Hpb 2009;11:510-5.

4. Penna C, Nordlinger B. Surgery of liver metastases from colorectal cancer: New promises. Br Med Bull 2002;64:127-40.

5. Esnaola NF, Meyer JE, Karachristos A, et al. Evaluation and management of intrahepatic and extrahepatic cholangiocarcinoma. Cancer 2016;122:1349-69.

6. Razumilava N, Gores GJ. Cholangiocarcinoma. Lancet 2014;383:2168-79.

7. Schwarz RE, Smith DD. Trends in local therapy for hepatocellular carcinoma and survival outcomes in the US population. Am J Surg 2008;195:829-36.

8. Saxena A, Chua TC, Perera M, et al. Surgical resection of hepatic metastases from neuroendocrine neoplasms: A systematic review. Surg Oncol 2012;21:e131-41.

9. Rossi RE, Massironi S, Spampatti MP, et al. Treatment of Liver Metastases in Patients with Digestive Neuroendocrine Tumors. J Gastrointest Surg 2012;16:1981-92.

10. Dasari BVM, Hodson J, Roberts KJ, et al. Developing and validating a pre-operative risk score to predict posthepatectomy liver failure. Hpb 2019;21:539-46.

11. Kamiyama T, Nakanishi K, Yokoo H, et al. Perioperative management of hepatic resection toward zero mortality and morbidity: Analysis of 793 consecutive cases in a single institution. J Am Coll Surg 2010;211:443-9.

12. Olthof PB, Tomassini F, Huespe PE, et al. Hepatobiliary scintigraphy to evaluate liver function in associating liver partition and portal vein ligation for staged hepatectomy: Liver volume overestimates liver function. Surgery 2017;162:775-83.

13. Sparrelid E, Jonas E, Tzortzakakis A, et al. Dynamic
Evaluation of Liver Volume and Function in Associating Liver Partition and Portal Vein Ligation for Staged Hepatectomy. J Gastrointest Surg 2017;21:967-74.

14. Kim D, Cornman-Homonoff J, Madoff DC. Preparing for liver surgery with "Alphabet Soup": PVE, ALPPS, TAE-PVE, LVD and RL. Hepatobiliary Surg Nutr 2020;9:136-51.

15. Hoekstra LT, van Lienden KP, Doets A, et al. Tumor progression after preoperative portal vein embolization. Ann Surg 2012;256:812-7.

16. Pamecha V, Levene A, Grillo F, et al. Effect of portal vein embolisation on the growth rate of colorectal liver metastases. Br J Cancer 2009;100:617-22.

17. de Graaf W, Van Den Esschert JW, Van Lienden KP, et al. Induction of tumor growth after preoperative portal vein embolization: Is it a real problem? Ann Surg Oncol 2009;16:423-30.

18. Brouquet A, Belghiti J. Chemotherapy and its effect on liver hypertrophy: Implications for portal vein embolization and resection. Semin Intervent Radiol 2008;25:162-7.

19. Hasselgren K, Sandström P, Björnsson B. Role of associating liver partition and portal vein ligation for staged hepatectomy in colorectal liver metastases: A review. World J Gastroenterol 2015;21:4491-8.

20. Kang D, Schadde E. Hypertrophy and Liver Function in ALPPS: Correlation with Morbidity and Mortality. Visc Med 2017;33:426-33.

21. Stockmann M, Bednarsch J, Malinowski M, et al. Functional considerations in ALPPS - consequences for clinical management. Hpb 2017;19:1016-25.

22. Vivarelli M, Vincenzi P, Montalti R, et al. ALPPS Procedure for extended liver resections: A single centre experience and a systematic review. PLoS One 2015;10:e0144019.

23. Matsuo K, Murakami T, Kawaguchi D, et al. Histologic features after surgery associating liver partition and portal vein ligation for staged hepatectomy versus those after hepatectomy with portal vein embolization. Surgery 2016;159:1289-98.

24. Matsuo K, Hiroshima Y, Yamazaki K, et al. Immaturity of Bile Canalicular-Ductule Networks in the Future Liver Remnant While Associating Liver Partition and Portal Vein Occlusion for Staged Hepatectomy (ALPPS). Ann Surg Oncol 2017;24:2456-64.

25. Jakobs TF, Saleem S, Atassi B, et al. Fibrosis, portal hypertension, and hepatic volume changes induced by intra-arterial radiotherapy with $90 \mathrm{Yttrium}$ microspheres. 
Dig Dis Sci 2008;53:2556-63.

26. Gaba RC, Lewandowski RJ, Kulik LM, et al. Radiation lobectomy: Preliminary findings of hepatic volumetric response to lobar yttrium-90 radioembolization. Ann Surg Oncol 2009; 16:1587-96.

27. Vouche M, Lewandowski RJ, Atassi R, et al. Radiation lobectomy: time-dependent analysis of future liver remnant volume in unresectable liver cancer as a bridge to resection. J Hepatol 2013;59:1029-36.

28. Teo JY, Allen JC, Ng DC, et al. A systematic review of contralateral liver lobe hypertrophy after unilobar selective internal radiation therapy with Y90. Hpb 2016;18:7-12.

29. Shah JL, Zendejas-Ruiz IR, Thornton LM, et al. Neoadjuvant transarterial radiation lobectomy for colorectal hepatic metastases: A small cohort analysis on safety, efficacy, and radiopathologic correlation. J Gastrointest Oncol 2017;8:E43-51.

30. Lewandowski RJ, Donahue L, Chokechanachaisakul A, et al. $90 \mathrm{Y}$ radiation lobectomy: Outcomes following surgical resection in patients with hepatic tumors and small future liver remnant volumes. J Surg Oncol 2016;114:99-105.

31. Gabr A, Abouchaleh N, Ali R, et al. Outcomes of Surgical Resection after Radioembolization for Hepatocellular Carcinoma. J Vasc Interv Radiol 2018;29:1502-10.e1.

32. Justinger C, Kouladouros K, Gärtner D, et al. Liver resection after selective internal radiotherapy (SIRT): Proof of concept, initial survival, and safety. J Surg Oncol 2015;112:436-42.

33. Wright GP, Marsh JW, Varma MK, et al. Liver Resection After Selective Internal Radiation Therapy with Yttrium-90 is Safe and Feasible: A Bi-institutional Analysis. Ann Surg Oncol 2017;24:906-13.

34. Melstrom LG, Eng OS, Raoof M, et al. Is hepatectomy safe following Yttrium-90 therapy? A multi-institutional international experience. Hpb 2019;21:1520-6.

35. National Cancer Institute. Common Terminology Criteria for Adverse Events (CTCAE) Version 5.0 [Internet] 2017 [cited 2019 Dec 12]. Available online: https://ctep.cancer. gov/protocolDevelopment/electronic_applications/docs/ CTCAE_v5_Quick_Reference_8.5x11.pdf

36. Dindo D, Demartines N, Clavien PA. Classification of surgical complications: A new proposal with evaluation in a cohort of 6336 patients and results of a survey. Ann Surg 2004;240:205-13.

37. Koch M, Garden OJ, Padbury R, et al. Bile leakage after hepatobiliary and pancreatic surgery: A definition and grading of severity by the International Study Group of Liver Surgery. Surgery 2011;149:680-8.
38. Rahbari NN, Garden OJ, Padbury R, et al. Posthepatectomy haemorrhage: A definition and grading by the International Study Group of Liver Surgery (ISGLS). Hpb 2011;13:528-35.

39. Rahbari NN, Garden OJ, Padbury R, et al. Posthepatectomy liver failure: A definition and grading by the International Study Group of Liver Surgery (ISGLS). Surgery 2011;149:713-24.

40. Strasberg SM. Nomenclature of hepatic anatomy and resections: A review of the Brisbane 2000 system. J Hepatobiliary Pancreat Surg 2005;12:351-5.

41. Toskich BB, Liu DM. Y90 Radioembolization Dosimetry: Concepts for the Interventional Radiologist. Tech Vasc Interv Radiol 2019;22:100-11.

42. Salem R, Thurston KG. Radioembolization with 90Yttrium microspheres: a state-of-the-art brachytherapy treatment for primary and secondary liver malignancies. Part 1: Technical and methodologic considerations. J Vasc Interv Radiol 2006;17:1251-78.

43. Arreaza JA, Tsamalaidze L, Stauffer J. Transarterial Radiation Lobectomy, Portal Vein Embolization, and Staged Hepatectomy for Multiple Bilobar Metachronous Colorectal Liver Metastasis. Am Surg 2018;84:e144-6.

44. Hoekstra LT, Van Lienden KP, Verheij J, et al. Enhanced tumor growth after portal vein embolization in a rabbit tumor model. J Surg Res 2013;180:89-96.

45. Schnitzbauer AA, Lang SA, Goessmann H, et al. Right portal vein ligation combined with in situ splitting induces rapid left lateral liver lobe hypertrophy enabling 2-staged extended right hepatic resection in small-for-size settings. Ann Surg 2012;255:405-14.

46. Schadde E, Ardiles V, Slankamenac K, et al. ALPPS offers a better chance of complete resection in patients with primarily unresectable liver tumors compared with conventional-staged hepatectomies: Results of a multicenter analysis. World J Surg 2014;38:1510-9.

47. Schadde E, Ardiles V, Robles-Campos R, et al. Early survival and safety of ALPPS first report of the international ALPPS registry. Ann Surg 2014;260:829-36.

48. Huiskens J, Schadde E, Lang H, et al. Avoiding postoperative mortality after ALPPS-development of a tumor-specific risk score for colorectal liver metastases. Hpb 2019;21:898-905.

49. Ahmed AF, Samreen N, Grajo JR, et al. Angiosomal radiopathologic analysis of transarterial radioembolization for the treatment of hepatocellular carcinoma. Abdom Radiol (NY) 2018;43:1825-36.

50. Gabr A, Riaz A, Mouli S, et al. Modified Radiation 
Lobectomy: An Evolving Paradigm to Convert Patients to Liver Resection Candidacy. Semin Intervent Radiol 2019;36:343-8.

51. Siddiqi NH, Devlin PM. Radiation Lobectomy-A Minimally Invasive Treatment Model for Liver Cancer: Case Report. J Vasc Interv Radiol 2009;20:664-9.

52. Cho SH, Kang UR, Kim JD, et al. The value of gadoxetate disodium-enhanced MR imaging for predicting posthepatectomy liver failure after major hepatic resection: A preliminary study. Eur J Radiol 2011;80:e195-200.

53. Geisel D, Raabe P, Lüdemann L, et al. Gd-EOB-DTPAenhanced MRI for monitoring future liver remnant function after portal vein embolization and extended hemihepatectomy: A prospective trial. Eur Radiol 2017;27:3080-7.

54. Vauthey JN, Zimmitti G, Kopetz SE, et al. RAS mutation status predicts survival and patterns of recurrence in patients undergoing hepatectomy for colorectal liver metastases. Ann Surg 2013;258:619-26.

55. Amikura K, Akagi K, Ogura T, et al. The RAS mutation status predicts survival in patients undergoing hepatic resection for colorectal liver metastases: The results from a genetic analysis of all-RAS. J Surg Oncol 2018;117:745-55.

56. Okuno M, Goumard C, Kopetz S, et al. RAS Mutation is Associated with Unsalvageable Recurrence Following Hepatectomy for Colorectal Cancer Liver Metastases. Ann Surg Oncol 2018;25:2457-66.

57. Agopian VG, Harlander-Locke M, Zarrinpar A, et al. A novel prognostic nomogram accurately predicts hepatocellular carcinoma recurrence after liver transplantation: Analysis of 865 consecutive liver transplant recipients. J Am Coll Surg 2015;220:416-27.

58. Shah SA, Greig PD, Gallinger S, et al. Factors associated with early recurrence after resection for hepatocellular carcinoma and outcomes. J Am Coll Surg 2006;202:275-83.

59. Shah SA, Cleary SP, Wei AC, et al. Recurrence after liver resection for hepatocellular carcinoma: Risk factors, treatment, and outcomes. Surgery 2007;141:330-9.

60. Marventano S, Grosso G, Mistretta A, et al. Evaluation of four comorbidity indices and Charlson comorbidity index adjustment for colorectal cancer patients. Int J Colorectal Dis 2014;29:1159-69.

61. Hines RB, Chatla C, Bumpers HL et al. Predictive capacity of three comorbidity indices in estimating mortality after surgery for colon cancer. J Clin Oncol 2009;27:4339-45.

62. Charlson ME, Pompei P, Ales KL, et al. A new method of classifying prognostic comorbidity in longitudinal studies: development and validation. J Chronic Dis 1987;40:373-83.

63. Quan H, Li B, Couris CM, et al. Updating and validating the charlson comorbidity index and score for risk adjustment in hospital discharge abstracts using data from 6 countries. Am J Epidemiol 2011;173:676-82.

64. Bolder U, Brune A, Schmidt S, et al. Preoperative assessment of mortality risk in hepatic resection by clinical variables: A multivariate analysis. Liver Transpl Surg 1999;5:227-37.

65. Abbass MA, Slezak JM, DiFronzo LA. Predictors of early postoperative outcomes in 375 consecutive hepatectomies: a single-institution experience. Am Surg 2013;79:961-7.

66. Walrand S, Hesse M, Chiesa C, et al. The low hepatic toxicity per gray of $90 \mathrm{Y}$ glass microspheres is linked to their transport in the arterial tree favoring a nonuniform trapping as observed in posttherapy PET imaging. J Nucl Med 2014;55:135-40.

67. Gabr A, Kallini JR, Gates VL, et al. Same-day 90Y radioembolization: implementing a new treatment paradigm. Eur J Nucl Med Mol Imaging 2016;43:2353-9.

68. Palard X, Edeline J, Rolland Y, et al. Dosimetric parameters predicting contralateral liver hypertrophy after unilobar radioembolization of hepatocellular carcinoma. Eur J Nucl Med Mol Imaging 2018;45:392-401.

69. Garin E, Lenoir L, Rolland Y, et al. Dosimetry based on 99mTc-macroaggregated albumin SPECT/CT accurately predicts tumor response and survival in hepatocellular carcinoma patients treated with 90Y-loaded glass microspheres: preliminary results. J Nucl Med 2012;53:255-63.

70. Garin E, Lenoir L, Edeline J, et al. Boosted selective internal radiation therapy with $90 \mathrm{Y}$-loaded glass microspheres (B-SIRT) for hepatocellular carcinoma patients: A new personalized promising concept. Eur J Nucl Med Mol Imaging 2013;40:1057-68.

71. Bourien H, Palard X, Rolland Y, et al. Yttrium-90 glass microspheres radioembolization (RE) for biliary tract cancer: a large single-center experience Eur J Nucl Med Mol Imaging 2019;46:669-76.

Cite this article as: Ahmed A, Stauffer JA, LeGout JD, Burns J, Croome K, Paz-Fumagalli R, Frey G, Toskich B. The use of neoadjuvant lobar radioembolization prior to major hepatic resection for malignancy results in a low rate of post hepatectomy liver failure. J Gastrointest Oncol 2021;12(2):751761. doi: 10.21037/jgo-20-507 